\title{
Study of the Combustion , Pyrolysis Characteristics and Synergistic Effect of Co-hydrocharsation Products of Oil Shale and Rice HuskStudy of the Combustion , Pyrolysis Characteristics and Synergistic Effect of Co-hydrocharsation Products of Oil Shale and Rice Husk
}

Yaoxin LIU

Docter

Enyu Wang ( $D$ 823084761@qq.com )

SIE

Ze KAN

Student

Research

Keywords: oil shale, Rice husk, Hydrocharsization, Combustion characteristics, Pyrolysis characteristics, synergy

Posted Date: November 2nd, 2021

DOI: https://doi.org/10.21203/rs.3.rs-995244/v1

License: (c) (i) This work is licensed under a Creative Commons Attribution 4.0 International License. Read Full License 


\title{
Study of the Combustion, Pyrolysis Characteristics and Synergistic Effect of Co-hydrocharsation Products of Oil Shale and Rice Husk
}

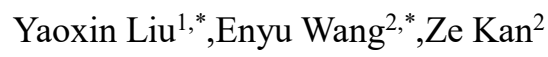

1 School of Energy and Power,Shenyang Institute of Engineerin,Shenyang 110136,China.

2 graduate faculty,Shenyang Institute of Engineering,Shenyang 110136,China;1950780548@qq.com(Z.K.)

* Correspondence: liuyaoxin77@163.com(Y.L.);823084761@qq.com(E.W.)

\begin{abstract}
Under the pressure of environmental problems and fossil energy shortage, countries all over the world are looking for fuel to replace fossil energy. Oil shale and rice husk are potential fuels, but they both have some problems, such as high ash content and low calorific value .In the present study,oil shale and rice husk were used as feedstock for the high quality fuel through hydrothermal approach,it provides a new way for the resource utilization of oil shale and rice.Thermogravimetric method was used to analyze the functional groups change and thermal transformation characteristics of mixed hydrochars prepared for oil shale(OS) and rice husk(RH) at different hydrothermal temperatures $\left(150,200\right.$ and $\left.250^{\circ} \mathrm{C}\right)$, including combustion and pyrolysis processes, and analyze the synergistic effects. Results showed that the co-hydrocharsization pretreatment had a significant effect on the thermal transformation behavior of oil shale and rice husk.On the one hand, the mixture of hydrocar has higher volatile content than its calculated value.On the other hand,a synergistic effect(promoting combustion and pyrolysis behavior) was found in both combustion and pyrolysis processes, and this effect was the most obvious when the hydrothermal temperature was around $200^{\circ} \mathrm{C}$, and the characteristic peak of functional groups vibration was strong. Since the synergistic effect of pyrolysis process is lower than that of combustion process, co-hydrocharsation products are considered to be more suitable for combustion. These findings have positive significance of energy generation and utilization of organic waste by the combination of co-hydrocharsization modification and subsequent thermochemical process.
\end{abstract}

Keywords:oil shale;Rice husk;Hydrocharsization;Combustion characteristics;Pyrolysis characteristics;synergy

\section{Introduction}

Oil shale has been explored by researchers and found to be a fuel to deep development potential, and has huge reserves all over the world[1].However, researchers also have found that oil shale has a high ash content,resulting in weak combustion reaction ability in the later stage,so it is difficult to large-scale combustion alone[2].Biomass is the advantages of extensive sources, including renewable and less combustion pollutants, and it is considered to be an important component of the world energy in the future[3].But it contains a number of alkaline metals easy to cause a large amount of corrosion of the heating surface of combustion equipment[4].In recent years, hydrocharsization is an effective means of converting organic solid waste into solid fuel by heat treatment[5], it has attracted extensive attention to scholars at home and abroad. In fact, the high temperature and high pressure water vapor conditions in the reactor are similar to the natural carbonization process, which is considered to be the simulation of the natural carbonization process[6].

Researchers, have the large body of research, use the different raw materials by co-hydrocharsization to produce solid hydrochars fuel, some scholars[7, 8] used sludge with lignite through hydrocharsization and research combustion and pyrolysis characteristics of hydrochars, found product of co-hydrocharsizations has higher carbon yield, and promoted the combustion and pyrolysis behavior.Some other scholars[9-11] studied the combustion performance of product by co-hydrocharsization of biomass and PVC, and found that the combustion performance of the hydrochars was better than that of raw materials at $200^{\circ} \mathrm{C}$, but the removal of chlorine in PVC was impeded by biomass. Researchers who co-hydrocharsization of coal and biomass[12,13] found that, the hydrochars content 
is the best at $230^{\circ} \mathrm{C}$, and the combustion index which is close to bituminous coal is the highest.Most researchers have found that the co-hydrocharsization of two materials with different properties has more advantages than the hydrocharsization produced from a single material.

To sum up,oil shale and rice husk have huge reserves,and there are certain problems of the combustion and utilization of oil shale and rice husk alone. If improving the quality of the mixed fuel to oil shale and rice husk through hydrocharsization, can reduce the unfavorable factors of both and maximize the advantages of both as fuels. Therefore, in this paper,thermogravimetric method was used to conduct combustion and pyrolysis characteristics test and kinetics analysis on the mixture of oil shale and rice husk, which will provide some theoretical reference for the large-scale application of oil shale and rice husk in the future.

\section{Materials and Methods}

\subsection{Test Materials}

Oil shale (OS) was taken from a coal farm in Jilin Province, and rice husk(RH) was taken from a grain factory in Liaoning Province.The raw materials were natural air-dried and crushed to a particle size less than $0.2 \mathrm{~mm}$.Previous studies have found that when the mass ratio of biomass to coal is $1: 1$,hydrothermal charcoal has great combustion characteristics and synergistic effect.Therefore, oil shale and rice husk are evenly mixed according to the mass ratio of $1: 1$, and the mixture is named Mix.Before the experiment, the sample was placed in a $105^{\circ} \mathrm{C}$ of constant-temperature drying oven (Shanghai light instrument equipment 101a-00) for 24h,and then sealed for use. Proximate and ultimate analysis of samples are shown in Table 1.

Table 1. Proximate and ultimate analysis of the raw

\begin{tabular}{|c|c|c|c|c|c|c|c|c|c|}
\hline \multirow{2}{*}{ Sample } & \multicolumn{4}{|c|}{ Proximate analysis/wt.\% } & \multicolumn{5}{|c|}{ Ultimate analysis/wt.\% } \\
\hline & M & Ash & VM & $\mathrm{FC}^{\mathrm{a}}$ & $\mathrm{C}$ & $\mathrm{H}$ & $\mathrm{O}^{\mathrm{b}}$ & $\mathrm{N}$ & $\mathrm{S}$ \\
\hline RH & 8.48 & 19.62 & 59.98 & 11.92 & 35.34 & 5.37 & 30.11 & 0.95 & 0.13 \\
\hline OS & 3.84 & 80.53 & 13.15 & 2.48 & 8.45 & 1.51 & 5.98 & 1.02 & 1.04 \\
\hline
\end{tabular}

\subsection{Preparation of Hydrochars}

The hydrocharsization test was carried out in a small high temperature and pressure reactor chamber.The material of the reactor chamber was Hastelloy alloy, the maximum working temperature was $300^{\circ} \mathrm{C}$, the pressure was $20 \mathrm{MPa}$, and the volume of the chamber was $150 \mathrm{~mL}$. To avoid the influence of impurities in water on the hydrolysis of raw materials and ensure the accuracy of the experiment, the solution was selected as deionized water.Considering the working conditions of the experimental equipment and the pyrolysis temperature of cellulose[14],the hydrothermal reaction temperatures were selected as 150,200 and $250^{\circ} \mathrm{C}$. Raw is the Raw material control,the specific reaction conditions are shown in the table.

Table 2. Sample reaction conditions

\begin{tabular}{|c|c|c|c|c|}
\hline \multicolumn{2}{|c|}{ Sample } & \multirow{2}{*}{$\begin{array}{c}\begin{array}{c}\text { hydrothermal } \\
\text { temperature } /{ }^{\circ} \mathrm{C}\end{array} \\
0\end{array}$} & \multirow{2}{*}{$\frac{\mathrm{RH} / \% \text { (mass) }}{0}$} & \multirow{2}{*}{$\frac{\mathrm{OS} / \%(\mathrm{mass})}{100}$} \\
\hline \multirow{4}{*}{ OS } & OS-Raw & & & \\
\hline & OS-150 & 150 & 0 & 100 \\
\hline & OS-200 & 200 & 0 & 100 \\
\hline & OS-250 & 250 & 0 & 100 \\
\hline \multirow{4}{*}{$\mathrm{RH}$} & RH-Raw & 0 & 100 & 0 \\
\hline & RH-150 & 150 & 100 & 0 \\
\hline & RH-200 & 200 & 100 & 0 \\
\hline & RH-250 & 250 & 100 & 0 \\
\hline \multirow{2}{*}{ Mix } & Mix-Raw & 0 & 50 & 50 \\
\hline & Mix-150 & 150 & 50 & 50 \\
\hline
\end{tabular}




$\begin{array}{llll}\text { Mix-200 } & 200 & 50 & 50 \\ \text { Mix-250 } & 250 & 50 & 50\end{array}$

The test process was as follows: $10 \mathrm{~g}$ sample was placed in the reactor chamber, $100 \mathrm{~mL}$ deionized water was added,mixed evenly, nitrogen was pumped into the reactor chamber $(30 \mathrm{~mL} / \mathrm{min})$ for $5 \mathrm{~min}$ after the cover was put on, the air in the reactor chamber was drained,and the reactor chamber was sealed.It was heated at a rate of $10^{\circ} \mathrm{C}$ $/ \mathrm{min}$ and kept for a certain reaction time( $2 \mathrm{~h})$ after reaching the reaction temperature. When the time is up, take out the reactor chamber,cool it to room temperature, use metal screen to separate solid and liquid,collect solid sample, put the solid sample in $105^{\circ} \mathrm{C}$ of constant-temperature drying oven for $24 \mathrm{~h}$, and seal it for later use.

\subsection{Characterization and Methods}

Proximate analysis according to GBT28731-2012(china) standard determination of ash and volatile content of the sample,fixed carbon subtraction method was used to calculate.

The combustion and pyrolysis tests were carried out with the thermogravimetric analyzer of Mettler Toledo,and the crucible material was alumina.The protective gas was high purity nitrogen, and the gas flow rate was $50 \mathrm{~mL} / \mathrm{min}$. The combustion atmosphere is synthetic air,and the pyrolysis atmosphere is high purity nitrogen,and the gas flow rate is $50 \mathrm{~mL} / \mathrm{min}$. The initial temperature was room temperature,and the termination temperature was $900^{\circ} \mathrm{C}$. The heating rate was set at $20^{\circ} \mathrm{C} / \mathrm{min}$.

The surface functional groups were used by the Nicolet 67 Fourier transform infrared spectrometer made by Thermo Nicole Company(U.S.). The scanning interval was $750 \sim 4000 \mathrm{~cm}^{-1}$, and the diamond crystal tablet was used.The test method is Fourier transform Attenuated total reflection infrared spectroscopy(ATR-FTIR).

\section{Results and Discussion}

\subsection{Proximate Analysis of Hydrochars}

Table 3 shows the Proximate analysis of Hydrochars under different reaction conditions.It can be seen that the fixed carbon content of the three raw materials increased significantly after hydrocharsization treatment,but the hydrothermal temperature had different effects on them. When the hydrothermal temperature is $150^{\circ} \mathrm{C}$,the fixed carbon content in oil shale increases from $5.29 \%$ to $14.02 \%$,the hydrothermal temperature continues to increase, the fixed carbon content increases less than $2 \%$, and ash content increases. This is due to the fact that oil shale contains a large number of light volatile content. When the hydrothermal temperature is low,organic matter is hydrolyzed[15] and small molecular compounds are generated. Subsequently, some small molecular compounds in the liquid phase undergo condensation reaction. At the same time, a small amount of ash dissolved in the liquid phase increases the fixed carbon content. When the hydrothermal temperature is less than $200^{\circ} \mathrm{C}$, the contents of fixed carbon and volatile matter in rice husk hydrochars change little,because the physical structure of cellulose is destroyed and hydrolyzed,hydrolyzed products undergo a series of chemical reactions such as dehydration,isomerization,etc.And generate some intermediate products of hydroxymethylfurfural or furfural and its derivatives[16].However,due to the low reaction intensity and small decomposition amount, the change of fixed carbon and volatiles in hydrochars is small.As the temperature increased to $250^{\circ} \mathrm{C}$, the fixed carbon content decreased from $15.75 \%$ to $25.35 \%$, and the volatile content decreased from $64.23 \%$ to $50.92 \%$. The main reason are that at this hydrothermal temperature,a large amount of cellulose hydrolyzes and deoxidizes, and functional groups such as $\mathrm{CH}$ and $\mathrm{OH}$ are destroyed. At the same time,aromatic chemical reactions to hydrochars further condense and recombine to generate macromolecular compounds[16].

Table 3 Proximate analysis of hydrochars

\begin{tabular}{cccc}
\hline & & Proximate analysis/wt.\% & \\
\cline { 2 - 4 } Sample & FC & VM & Ash \\
\hline OS-Raw & 5.29 & 15.67 & 79.04 \\
OS-150 & 14.02 & 10.21 & 75.77 \\
OS-200 & 14.58 & 9.69 & 77.73
\end{tabular}




$\begin{array}{cccc}\text { OS-250 } & 15.72 & 6.09 & 78.19 \\ \text { RH-Raw } & 12.78 & 70.11 & 17.11 \\ \text { RH-150 } & 12.47 & 69.22 & 18.31 \\ \text { RH-200 } & 15.75 & 64.23 & 20.02 \\ \text { RH-250 } & 25.35 & 50.92 & 23.73 \\ \text { Mix-Raw } & 9.82 & 41.67 & 48.51 \\ \text { Mix-150 } & 12.29 & 40.53 & 47.18 \\ \text { Mix-200 } & 13.28 & 35.87 & 50.85 \\ \text { Mix-250 } & 14.91 & 30.33 & 54.76 \\ \text { Mix-Raw(th) } & 9.07 & 42.86 & 48.07 \\ \text { Mix-150(th) } & 13.25 & 39.71 & 47.04 \\ \text { Mix-200(th) } & 15.19 & 35.94 & 48.87 \\ \text { Mix-250(th) } & 20.56 & 28.49 & 50.95\end{array}$

Note: th is the calculated value.

Compared with the theoretical calculation value of the mixture hydrochars, the experimental mixture hydrochars is less affected by the hydrothermal temperature. With the increase in hydrothermal temperature, the fixed carbon content increases, while the volatile content decreases, which is consistent with the change of the first two raw materials with hydrothermal temperature.The fixed carbon content is lower than the theoretical value, while the volatile content is higher.This may be due to the carbonate or alkaline earth metal oxides in oil shale that hinder the hydrolysis of cellulose in rice husk[17] and inhibit the deoxidation and decarboxylation reactions.

\subsection{Chemical Structure Analysis of Hydrochars}

In Figure 1(a,b and c),the wide peak of wave number $3620 \sim 3300 \mathrm{~cm}^{-1}$ corresponds to the O-H bending vibration peak, the absorption peak of wave number $2900 \sim 2850 \mathrm{~cm}^{-1}$ is the stretching vibration peak of $\mathrm{C}-\mathrm{H}$ bond between aliphatic group, and the characteristic peak of benzene ring structure in the range of $1700 \sim 1370 \mathrm{~cm}^{-1} .1030 \sim 1060 \mathrm{~cm}^{-}$ ${ }^{1}$ is the stretching vibration of $\mathrm{C}-\mathrm{OH}$ bond in hydroxyl,ester and ether[18]. As can be seen from Figure 1(a), the infrared spectra of the hydrocharss obtained are basically similar to the characteristic peaks of the main groups except for some wave peak intensity changes.After hydrocharsization treatment for $150{ }^{\circ} \mathrm{C}$, the light volatiles hydrolyzed and produced a large number of esters and ether compounds. The characteristic peak vibration intensity of functional groups of hydrochars of oil shale was intense. However, as the hydrothermal temperature continues to rise, $\mathrm{O}-\mathrm{H}, \mathrm{C}-\mathrm{H}$ and $\mathrm{C}-\mathrm{O}$ bonds break during further pyrolysis of oil shale, and the vibration intensity of characteristic peaks of functional groups becomes smaller and smaller, which is close to that of raw materials.As shown in Figure 1(b),the variation on characteristic peak vibration intensity of functional groups of rice husk hydrochars is basically consistent with that of oil shale hydrochars, but the characteristic peak intensity of benzene ring structure basically does not change with the increase of hydrothermal temperature,indicating that the benzene ring structure of rice husk hydrochars is relatively stable.Figure 1(c) shows the FTIR diagram of the hydrochars mixture. When the hydrothermal temperature is $200^{\circ} \mathrm{C}$, the characteristic peaks of $\mathrm{C}-\mathrm{H}$ and $\mathrm{C}-\mathrm{O}$ functional groups of the hydrochars show strong vibration, which is due to the hydrolysis of hemicellulose and cellulose in rice husk to generate a large number of fatty family compounds. The vibration of characteristic peak decreases from the increase in hydrothermal temperature,indicating that the macromolecule compounds are hydrolyzed further.

\subsection{Combustion Characteristics of Hydrochars}

\subsubsection{Analysis of Combustion TG and DTG Curves}

The TG and DTG curves of the three raw materials and their hydrochars combustion process is shown in Figure 2, Figure 3 and Figure 4. Taking the theoretical TG and DTG curves of the co-hydrochars with a mixture of $150^{\circ} \mathrm{C}$ as an example,the TG and DTG curves are calculated by Formula (1).

$$
T G_{t h-150}=0.5 T G o s-150+0.5 T G_{R H}-150
$$

Where, 0.5 is the mixing ratio of $\mathrm{OS}$ and $\mathrm{RH}$,and TGos-150 and $\mathrm{TG}_{\mathrm{RH}-150}$ represent the weight loss of OS-150 
and $\mathrm{RH}-150$ respectively.

According to the DTG curve in Figure 2,there are three obvious weightlessness peaks of oil shale.The first peak $\left(<150^{\circ} \mathrm{C}\right)$ is the mass loss caused by water evaporation. The second peak $\left(250 \sim 650^{\circ} \mathrm{C}\right)$ is mainly caused by the release of gaseous products caused by the volatilized analysis or decomposition of organic compounds[19] and the combustion of partially fixed carbon. The third peak $\left(650 \sim 750^{\circ} \mathrm{C}\right)$ was caused by the slow combustion of residual fixed carbon and the pyrolysis reaction to other inorganic materials such as carbonate and alkaline earth minerals. After hydrothermal treatment,part of salt and alkaline earth minerals are dissolved in water,resulting in a decrease in ash contents in oil shale and a downward TG curve. With the increase in hydrothermal temperature, the volatile content of hydrochars decreased slightly,while the ash content increased,showing that the second and third peaks values of DTG gradually decreased,but the hydrothermal temperature had little influence on the variation range of DTG curve of hydrochars of oil shale.

Figure 3 shows that the hydrochars combustion process of rice husk is also divided into three stages. The first stage $\left(<150^{\circ} \mathrm{C}\right)$ is caused by water loss. In the second stage $\left(250 \sim 400^{\circ} \mathrm{C}\right)$, DTG curve showed a large peak value,indicating that rice husk hydrothermal charcoal may contain more lighter volatile matter[20], and a large amount of hemicellulose and cellulose are precipitated in the form of gas phase. Therefore, rice husk combustion is mainly light volatile matter; The third stage $\left(400 \sim 600^{\circ} \mathrm{C}\right)$ is mainly characterized by slow lignin combustion, which is characterized by small peak value and wide range of DTG curve. With the increase of hydrothermal temperature, volatile content decreased and fixed carbon content increased,showing that the second peak value of DTG curve gradually decreased and the third peak value gradually increased. When the hydrothermal temperature is $150^{\circ} \mathrm{C}$, the hydrolysis reaction to organic matter is dominant and a large number of intermediates are generated.Some intermediates generate stabler carbon-carbon double bonds between polymerization[21],so the weight loss rate increases compared with raw materials. When the hydrothermal temperature is $250^{\circ} \mathrm{C}$, the excessive hydrothermal temperature leads to the hydrolysis of hemicellulose and a large amount of cellulose, which is decomposed into small molecule compounds dissolved in water,and some small molecule compounds are condensed to generate pseudolignin substances[22], which leads to a significant decrease in the combustion rate of volatiles in THE DTG curve.In addition,the backward ignition temperature indicates that hydrothermal treatment can shorten the combustion time of hydrochars.

Figure 4 plots TG and DTG curves of oil shale and rice husk hydrochars combustion process, including experimental curves and calculation curves. From the image, it can be intuitively found that the combustion curve is similar to that of rice husk,indicating that rice husk plays a dominant role in the combustion process of mixed hydrothermal charcoal. There are two main combustion peaks at the DTG curve, which may be because some salts or alkaline earth metals in oil shale promote the pyrolysis of part of lignin in rice husk[23], leading to the transfer of fixed carbon combustion to low temperature, thus making the combustion process of the mixture of hydrochars more stable.Compared with the calculated curve, it can also be found that the fixed carbon combustion section is close to the volatile combustion section. With the increase in hydrothermal temperature, the combustion peaks of volatile and fixed carbon of hydrochars are obviously higher than the calculated curve. These results indicate that the synergistic effect between oil shale and rice husk makes the combustion process of the mixture of hydrochars more fully concentrated.

\subsubsection{Analysis of Combustion Characteristics}

Ignition and burnout temperatures are determined by TG-DTG curve joint definition method[24,25]. Combustion characteristics of samples are expressed by comprehensive combustion characteristics index $\mathrm{S}_{\mathrm{N}}[26]$, which can be expressed as:

$$
S_{N}=\frac{\left(d_{w} / d_{t}\right)_{\max }\left(d_{w} / d_{t}\right)_{\text {mean }}}{T_{i}^{2} T_{b}}
$$

Where, $(d w / d t) \max$ and $(d w / d t)$ mean are the maximum combustion rate and average combustion rate 
respectively, $\% / \mathrm{min} ; T_{i}$ is the ignition temperature, $\mathrm{K} ; T_{b}$ is burnout temperature, $\mathrm{K}$.

Table 4. Combustion characteristics of hydrochars

\begin{tabular}{|c|c|c|c|c|c|c|}
\hline \multirow[t]{2}{*}{ Sample } & \multicolumn{2}{|c|}{$\begin{array}{l}\text { Characteristic } \\
\text { temperatures } /{ }^{\circ} \mathrm{C}\end{array}$} & \multirow{2}{*}{$\begin{array}{l}\mathrm{t}_{\mathrm{b}} / \\
\min \end{array}$} & \multirow{2}{*}{$\begin{array}{c}(\mathrm{d} w / \mathrm{d} t)_{\max } / \\
\left(\%(\operatorname{mass}) \cdot \min ^{-1}\right)\end{array}$} & \multirow{2}{*}{$\begin{array}{c}(\mathrm{d} w / \mathrm{d} t)_{\text {mean }} / \\
\left(\%(\operatorname{mass}) \cdot \min ^{-1}\right)\end{array}$} & \multirow[t]{2}{*}{$S_{N} \times 10^{7}$} \\
\hline & $T_{i}$ & $T_{b}$ & & & & \\
\hline OS-Raw & 338.15 & 741.29 & 19.03 & 1.58 & 0.95 & 0.18 \\
\hline OS-150 & 309.34 & 751.26 & 22.51 & 1.70 & 0.97 & 0.23 \\
\hline OS-200 & 308.59 & 741.97 & 22.21 & 1.71 & 0.92 & 0.22 \\
\hline OS-250 & 308.91 & 741.64 & 22.22 & 1.64 & 0.90 & 0.21 \\
\hline RH-Raw & 254.38 & 556.80 & 16.31 & 13.39 & 5.14 & 19.10 \\
\hline RH-150 & 253.87 & 585.22 & 17.08 & 16.36 & 4.54 & 19.69 \\
\hline RH-200 & 285.44 & 575.92 & 15.51 & 14.54 & 4.69 & 14.53 \\
\hline RH-250 & 265.42 & 595.89 & 15.55 & 6.78 & 4.27 & 6.90 \\
\hline Mix-Raw & 265.64 & 712.22 & 22.52 & 6.51 & 2.20 & 2.85 \\
\hline Mix-150 & 265.67 & 702.50 & 22.02 & 7.62 & 2.32 & 3.57 \\
\hline Mix-200 & 286.95 & 702.26 & 21.07 & 8.27 & 2.22 & 3.18 \\
\hline Mix-250 & 276.87 & 692.52 & 21.01 & 5.56 & 2.10 & 2.20 \\
\hline $\operatorname{Mix}-\operatorname{Raw}(\mathrm{th})$ & 265.53 & 741.29 & 22.32 & 6.38 & 1.37 & 1.67 \\
\hline Mix-150(th) & 256.01 & 740.94 & 21.95 & 7.35 & 1.42 & 2.15 \\
\hline Mix-200(th) & 296.01 & 732.06 & 21.05 & 7.71 & 1.65 & 1.98 \\
\hline Mix-250(th) & 297.73 & 750.65 & 21.03 & 3.38 & 3.38 & 1.72 \\
\hline
\end{tabular}

Note: $t_{b}$ is the time from ignition to burnout.

The comprehensive combustion index $\left(\mathrm{S}_{\mathrm{N}}\right)$ of hydrochars was calculated in Table 4 to further to evaluate the combustion performance of the fuel. For oil shale, with the increase of hydrothermal temperature, the comprehensive combustion index $\mathrm{S}_{\mathrm{N}}$ firstly increased and then decreased,from $1.8 \times 10^{-8}$ when raw material to $2.3 \times 10^{-8}($ OS- 150$)$ and then decreased to $2.1 \times 10^{-8}($ OS-250). This may be due to the increase in ash content after hydrothermal treatment, which leads to some difficult-to-burn minerals blocking part of the pores[27], reducing its contact area with air, and thus limiting the combustion behavior of hydrothermal charcoal. After hydrothermal treatment,the comprehensive combustion index of rice husk has the same trend as that of oil shale, and reaches the maximum value $\left(1.97 \times 10^{-8}\right)$ at the hydrothermal temperature of $150^{\circ} \mathrm{C}$. However, with the increase of hydrothermal temperature, $\mathrm{S}_{\mathrm{N}}$ decreases greatly. As expected, the composite combustion index of the mixture was higher than the calculated value, and also reached the maximum value at $150^{\circ} \mathrm{C}\left(\mathrm{Calculated}\right.$ value: $2.15 \times 10^{-8}$; Experimental value: $\left.3.57 \times 10^{-8}\right)$.

\subsubsection{Analysis of Combustion Dynamics Parameters}

The combustion reaction to oil shale and rice husk hydrochars is a typical gas-solid reaction, and the relationship between combustion rate and temperature conforms to Arrhenius law for such a reaction process with slow heating up[28].Therefore, equations(3)and(4)can be used to describe the combustion process of hydrochars:

$$
\begin{aligned}
& f(\alpha)=(1-\alpha)^{n} \\
& \alpha=\frac{m_{o}-m_{7}}{m_{0}-m_{\infty}}
\end{aligned}
$$

Where, $a$ is the conversion rate, which can be obtained from the thermogravimetric curve according to Equation (4). $\mathrm{M}_{0}, \mathrm{M}_{\mathrm{T}}$ and $\mathrm{M}_{\infty}$ are the sample mass before the experiment, at the time of experiment $T$ and at the end of experiment respectively, $\mathrm{kg} ; \mathrm{n}$ is the reaction order.

The combustion rate equation can be expressed by Equation (5) : 


$$
\frac{d_{\alpha}}{d_{T}}=\frac{A}{\beta} \exp \left(-\frac{E}{R T}\right) f(\alpha)
$$

Where, $A$ is the pre-exponential factor, $\min ^{-1} ; \beta$ is heating rate, $\mathrm{K} / \mathrm{min} ; E$ is the activation energy, $\mathrm{kJ} / \mathrm{mol} ; R$ is the gas constant, $\mathrm{J} /(\mathrm{mol} \cdot \mathrm{K}) ; T$ is the absolute temperature, $\mathrm{K}$.

The coats-Redfern equation[29] was used to analyze the dynamics, and $n=1$ was used to calculate. Equations (3) and (5) were integrated simultaneously to obtain:

$$
\ln \left[-\frac{\ln (1-\alpha)}{T^{2}}\right]=\ln \left[\frac{A R}{\beta E}\left(1-\frac{2 R T}{E}\right)\right]-\frac{E}{R T}
$$

Where, ${ }^{1-\frac{2 R T}{E}} \approx 1, \ln \left[\frac{A R}{\beta E}\left(1-\frac{2 R T}{E}\right)\right] \approx \ln \frac{A R}{\beta E}$, as a constant,define $y=\ln \left[-\frac{\ln (1-\alpha)}{T^{2}}\right]$, $b=\ln \frac{A R}{\beta E}, k=-\frac{E}{R}, x=-\frac{1}{T}$, Where $\mathrm{k}$ and $\mathrm{b}$ are constants, substituted into Equation (6), equation (7) is obtained:

$$
y=k x+b
$$

The slope and intercept of the line can be obtained by eq.(7) to calculate $\mathrm{E}$ and A. As can be seen from Figure 2, 3 and 4,oil shale hydrothermal charcoal contains combustion peak and inorganic pyrolysis peak,and only combustion peak is calculated here, while rice husk and hybrid hydrothermal charcoal have two obvious combustion peaks,so the combustion kinetics parameters of the two peaks are analyzed respectively. The results are shown in

\begin{tabular}{|c|c|c|c|c|c|}
\hline Sample & Temperature $T /{ }^{\circ} \mathrm{C}$ & Fitted equation & $\begin{array}{l}\text { Activationenergy } \\
E /\left(\mathrm{kJ} \cdot \mathrm{mol}^{-1}\right)\end{array}$ & $\begin{array}{c}\text { Frequency } \\
\text { factor } A / \mathrm{min}^{-1}\end{array}$ & $\begin{array}{c}\text { Correlationcoefficient } \\
\qquad R^{2} \\
\end{array}$ \\
\hline \multirow{2}{*}{ OS-Raw } & $338.15 \sim 643.21$ & $y=-4292.42 x-8.222$ & 35.69 & $2.31 \times 10$ & 0.99 \\
\hline & $662.73 \sim 741.29$ & $y=-6354.72 x-6.379$ & 52.83 & $2.16 \times 10^{2}$ & 0.93 \\
\hline \multirow{2}{*}{ OS-150 } & $309.34 \sim 643.28$ & $y=-3406.96 x-9.174$ & 28.33 & 7.06 & 0.99 \\
\hline & $672.59 \sim 751.26$ & $y=-5785.83 x-6.957$ & 48.10 & $1.1 \times 10^{2}$ & 0.93 \\
\hline \multirow{2}{*}{ OS-200 } & $308.59 \sim 643.73$ & $y=-3352.86 x-9.196$ & 27.88 & 6.78 & 0.99 \\
\hline & $653.51 \sim 741.97$ & $y=-5293.14 x-7.402$ & 44.01 & $6.45 \times 10$ & 0.92 \\
\hline \multirow{2}{*}{ OS-250 } & $308.91 \sim 643.56$ & $y=-3623.28 x-8.866$ & 30.12 & $1.02 \times 10$ & 0.99 \\
\hline & $653.56 \sim 741.64$ & $y=-4296.11 x-8.382$ & 35.72 & $1.97 \times 10$ & 0.93 \\
\hline \multirow{2}{*}{ RH-Raw } & $264.8 \sim 381.86$ & $y=-6703.57 x-2.419$ & 55.73 & $1.19 \times 10^{4}$ & 0.94 \\
\hline & $391.87 \sim 584.48$ & $y=-3488.22 x-7.881$ & 29.01 & $2.64 \times 10$ & 0.92 \\
\hline \multirow{2}{*}{ RH-150 } & $264.24 \sim 391.25$ & $y=-6237.83 x-3.433$ & 51.86 & $4.03 \times 10^{3}$ & 0.94 \\
\hline & $420.67 \sim 603.64$ & $y=-4291.89 x-7.007$ & 35.68 & $7.77 \times 10$ & 0.95 \\
\hline \multirow{2}{*}{ RH-200 } & $285.44 \sim 380.85$ & $y=-6802.38 x-2.638$ & 56.56 & $9.73 \times 10^{3}$ & 0.96 \\
\hline & $390.74 \sim 594.13$ & $y=-3047.32 x-8.772$ & 25.34 & 9.44 & 0.93 \\
\hline \multirow{2}{*}{ RH-250 } & $286.85 \sim 361.29$ & $y=-5299.37 x-5.458$ & 44.06 & $4.51 \times 10^{2}$ & 0.98 \\
\hline & $371.34 \sim 613.71$ & $y=-4291.12 x-7.397$ & 35.68 & $5.26 \times 10$ & 0.93 \\
\hline \multirow{2}{*}{ Mix-Raw } & $265.64 \sim 380.74$ & $y=-7026.22 x-2.221$ & 58.42 & $1.52 \times 10^{4}$ & 0.93 \\
\hline & $390.73 \sim 712.22$ & $y=-2263.48 x-9.945$ & 18.82 & 2.17 & 0.97 \\
\hline \multirow{2}{*}{ Mix-150 } & $265.67 \sim 381.60$ & $y=-7813.59 x-0.970$ & 64.96 & $5.92 \times 10^{4}$ & 0.97 \\
\hline & $391.52 \sim 702.50$ & $y=-1834.27 x-10.35$ & 15.25 & 1.17 & 0.92 \\
\hline Mix-200 & $286.95 \sim 383.21$ & $y=-8526.12 x-0.086$ & 70.89 & $1.56 \times 10^{5}$ & 0.96 \\
\hline
\end{tabular}
Table 5 .

Table 5. kinetic parameters of hydrochars combustion 


\begin{tabular}{cccccc} 
& $393.20 \sim 662.90$ & $y=-2236.34 x-9.821$ & 18.59 & 2.43 & 0.93 \\
Mix-250 & $276.87 \sim 362.46$ & $y=-9807.56 x+1.916$ & 81.54 & $1.33 \times 10^{6}$ & 0.98 \\
& $372.49 \sim 692.52$ & $y=-2380.95 x-9.756$ & 19.79 & 2.76 & 0.91 \\
Mix-Raw(th) & $265.53 \sim 381.86$ & $y=-5671.62 x-4.456$ & 47.15 & $1.32 \times 10^{3}$ & 0.93 \\
& $381.86 \sim 741.29$ & $y=-1944.94 x-10.41$ & 16.17 & 1.17 & 0.95 \\
Mix-150(th) & $256.01 \sim 400.98$ & $y=-5045.39 x-5.714$ & 41.95 & $3.32 \times 10^{2}$ & 0.98 \\
\multirow{3}{*}{ Mix-200(th) } & $400.98 \sim 740.94$ & $y=-2106.81 x-10.33$ & 17.52 & 1.37 & 0.94 \\
& $296.01 \sim 390.82$ & $y=-5412.64 x-5.223$ & 45.00 & $5.83 \times 10^{2}$ & 0.95 \\
Mix-250(th) & $390.82 \sim 732.06$ & $y=-2095.66 x-10.35$ & 17.42 & 1.34 & 0.92 \\
\hline
\end{tabular}

From table 5 shows, in addition to the oil shale, in a fixed carbon combustion activation energy of other samples are lower than in volatile combustion activation energy, this is mainly because of volatile combustion period,low temperature, low molecular energy,need high heat to promote molecular thermal motion,which leads to a high activation energy,and volatile part and fixed carbon combustion,also absorb more heat.In coke combustion section, lignin decomposition is slow, and coke with porous structure generated by pyrolysis of volatile combustion section[30] is conducive to the contact between oxygen molecules and carbon. Meanwhile, the combustion of volatile combustion section has fully preheated the sample,resulting in low activation energy in fixed carbon combustion section. The activation energy of the combustion section of the volatiles in the actual mixture of hydrochars is higher than the theoretical value, which is because the synergistic effect on the two generates more volatiles and requires more heat of absorption. The combustion segments of fixed carbon are all lower than the theoretical values, which may be due to the existence of a small amount of salt or alkaline earth minerals in hydrochars which promotes the combustion behavior and reduces the activation energy.

\subsubsection{Analysis of Synergistic Effect in Combustion Process}

In order to further clarify the synergistic effect of hydrochars mixture in the combustion process, taking the cohydrocharsization of the mixture at $150^{\circ} \mathrm{C}$ as an example,the theoretical calculation of hydrochars loss(TGMIX-150) and deviation (Deviation 150$)$ [31] are shown in Formula(1) and (8) respectively.

$$
\text { Deviation }_{150}=\frac{\left(T G_{\exp -150}-T G_{t h-150}\right)}{T G_{t h-150}} \times 100 \%
$$

Where, $\mathrm{TG}_{\mathrm{EXP}-150}$ is the experimental weight loss of Mix 150 . The theoretical calculated values and deviations of other parameters can be obtained by "weight loss $\left(\mathrm{TG}_{\times--}\right)$" in substitution Equation (8),and the results are shown in the figure 5 .

In general, when the deviation is greater than $2 \%$ (98\% confidence), it indicates low weight loss rate and high heat loss. When the deviation value is less than $-2 \%$, it indicates a strong synergistic effect,which is beneficial to the combustion process of the mixture[32].According to the above rules, it can be observed that the mixture pretreated by hydrocharsization has a low ignition point $\operatorname{Ti}\left(<290^{\circ} \mathrm{C}\right)$, and no synergistic effect occurs to the initial combustion stage $\left(<300^{\circ} \mathrm{C}\right)$. When the combustion temperature is higher than $350^{\circ} \mathrm{C}$, the synergistic effect is obvious. This is due to the interaction between raw materials:(1)oil shale catalyzes more decarboxylation reaction,improves the degree of coalification of the mixture, thus accelerating the actual combustion of the mixture;(2)The first release and combustion of light volatile compounds from rice husk can effectively improve the reactivity of oil shale and promote the combustion process of the mixture. With the increase in hydrothermal temperature,the synergistic effect is enhanced, and the maximum negative deviation is $10.12 \%$ at $250^{\circ} \mathrm{C}$, indicating that oil shale and rice husk achieve the maximum synergistic effect at this temperature. With the increase in hydrothermal temperature,there is a large positive deviation from volatile combustion stage $\left(250 \sim 350^{\circ} \mathrm{C}\right)$ and salt or alkaline earth metal decomposition stage $\left(600 \sim 900^{\circ} \mathrm{C}\right)[33]$, and the overall synergic effect of Mix-250 is smaller than that of Mix-200.Therefore,considering 
the combustion behavior,comprehensive combustion index and synergistic effects of hydrochars, Mix-200 is more suitable as a solid fuel.

\subsection{Pyrolysis characteristics of hydrochars}

\subsubsection{TG and DTG Curve Analysis of Hydrochars Pyrolysis}

When the carrier gas is pure $\mathrm{N}_{2}$, except for a simple thermal decomposition process similar to combustion, the pyrolysis process does not include the oxidation of the sample,but includes a thermochemical process combining heat and oxygen effects. Figure 6,Figure 7 and Figure 8 show the TG and DTG curves of raw material and hydrochars pyrolysis process.

Figure 6 shows that oil shale pyrolysis can be divided into three parts:The first part $\left(<150^{\circ} \mathrm{C}\right)$ is the mass loss caused by water evaporation, and the weight loss is less than $3 \%$. The second part $\left(200 \sim 600^{\circ} \mathrm{C}\right)$ is the stage of volatilization and partial fixed carbon pyrolysis. The maximum weight loss rate is around $450^{\circ} \mathrm{C}$, and a small weight loss peak to occur to $550^{\circ} \mathrm{C}$ for some samples. This is mainly due to the chemical bond fracture of organic compounds in oil shale and the transformation and degeneration of some functional groups to generate combustible gas and certain condensable volatiles[34].The weight loss rate of the whole part 2 is about $10 \%$, which is the main stage of oil shale pyrolysis process. The third part $\left(600 \sim 750^{\circ} \mathrm{C}\right)$ is mainly caused by the secondary cracking of the pyrolysis products (mainly tar and coke) in the second stage. At this stage, the tar and coke molecules are cracked and cracked into non-condensed gas phase products, and the weight loss in this stage is about 7\%. However, the oil shale contains a large amount of ash, including salts and alkaline earth metal oxides, and the mass is still decreasing after $750^{\circ} \mathrm{C}$. After hydrocharsization treatment, the weight loss curve of oil shale changes obviously, TG curve shows an overall upward shift, and with the increase of hydrothermal temperature,ash content increases, TG curve continues to move up.The DTG curve also changed significantly, and the maximum weight loss rate increased from 1.18 to 1.46 . With the increase in hydrothermal temperature, the peak value of $720^{\circ} \mathrm{C}$ gradually decreased.The results showed that the hydrothermal process resulted in the decrease of light volatile and the increase of heavy volatile and fixed carbon in oil shale,which was similar to that of Kambo H.S. The research conclusions[35] is relatively consistent. At the same time,the pyrolysis interval moves backward with the increase in hydrothermal temperature.

Figure 7 shows the weight loss curve (TG) and weight loss rate curve (DTG) of rice husk pyrolysis. The pyrolysis of rice husk is different from its combustion process, which is divided into two stages: 1) Water evaporation is consistent with the combustion process of $150^{\circ} \mathrm{C}$.2) $250 \sim 450^{\circ} \mathrm{C}$ is the main range of rice husk pyrolysis, the weight loss process is the most intense, mainly the decomposition reaction of cellulose and lignin in rice husk. After hydrocharsization treatment,TG curve moved upward and ash content increased.With the increase in hydrothermal temperature,the pyrolysis peak of hydrochars shifts slightly to a higher temperature than that of raw material. The maximum fuel rate is reached at the RH-200.Minimum in RH-250.This is because when the hydrothermal temperature is low,hemicellulose and a small amount of cellulose hydrolyze and accelerate the pyrolysis reaction, while when the hydrothermal temperature is high $\left(250^{\circ} \mathrm{C}\right)$, the main components of hydrochars are lignin and macromolecular compounds, so the pyrolysis reaction is slow.

Figure 8 shows the theoretical and experimental TG-DTG comparison curve of the pyrolysis process of the hydrochars mixture.According to the TG curve,the weight loss rate is high in the range of $250 \sim 350^{\circ} \mathrm{C}$, and the experimental weight loss rate is higher than the theoretical calculation value.This is because the oil shale mainly occurs in the process of pyrolysis two competing reaction,condensation and cracking of rice husk pyrolysis temperature is lower than that of the oil shale, needed to generate the $\mathrm{H}_{2}$ produced its first $\mathrm{H}_{2}$ inhibit shale condensation reaction, so as to promote the mixture to a certain extent of cracking reaction[36], finally accelerate the weight loss rate of the pyrolysis process. In addition, the alkali metal elements in rice husk can catalyze the pyrolysis process, which can promote the mixture pyrolysis and release gas products. DTG curve also shows that there is a certain synergistic effect of the pyrolysis process. With the increase in hydrothermal temperature, the 
maximum weight loss rate of pyrolysis increases first and then decreases, reaching the maximum at Mix-200, which is consistent with the pyrolysis change of rice husk hydrothermal charcoal.

\subsubsection{Analysis of Pyrolysis Characteristics}

In order to quantitatively evaluate the pyrolysis characteristics of samples, a comprehensive pyrolysis index (D)[37] was defined to compare the release characteristics of each sample during pyrolysis. The calculation formula is (10), and the calculation results are shown in Table 6.

$$
\begin{gathered}
M_{1}=1-M_{r} / 100 \\
D=\frac{(\mathrm{d} w / \mathrm{d} t)_{\max }(\mathrm{d} w / \mathrm{d} t)_{\operatorname{mean}} M_{1}}{T_{i} T_{m} \Delta T_{1 / 2}}
\end{gathered}
$$

Where, $(d w / d t)_{\max }$ and $(d w / d t)_{\text {mean }}$ are the maximum and average weight loss rates of the pyrolysis process, $\%$ (mass) $\cdot \mathrm{min}^{-1} ; M_{1}$ is the amount of pyrolysis mass loss, $\%$ (mass), $M_{\mathrm{r}}$ is the amount of residue after pyrolysis, $\%$ (mass); $T_{\mathrm{i}}$ represents the initial pyrolysis temperature, ${ }^{\circ} \mathrm{C} ; T_{\mathrm{m}}$ represents the temperature point corresponding to the maximum weight loss rate, ${ }^{\circ} \mathrm{C} ; \triangle T_{1 / 2}$ is Temperature interval of $(\mathrm{d} w / \mathrm{d} t)_{\max } /(\mathrm{d} w / \mathrm{d} t)_{\text {mean }}=0.5,{ }^{\circ} \mathrm{C}$.

\begin{tabular}{|c|c|c|c|c|c|c|c|}
\hline \multirow[t]{2}{*}{ Sample } & \multirow{2}{*}{$\begin{array}{l}\text { Residue/ } \\
\% \text { (mass) }\end{array}$} & \multicolumn{2}{|c|}{$\begin{array}{c}\text { Characteristic } \\
\text { temperatures } /{ }^{\circ} \mathrm{C}\end{array}$} & \multirow{2}{*}{$\begin{array}{c}(\mathrm{d} w / \mathrm{d} t)_{\max } / \\
\left(\%(\operatorname{mass}) \cdot \min ^{-1}\right)\end{array}$} & \multirow{2}{*}{$\begin{array}{c}(\mathrm{d} w / \mathrm{d} t)_{\text {mean }} / \\
\left(\%(\mathrm{mass}) \cdot \mathrm{min}^{-1}\right)\end{array}$} & \multirow[t]{2}{*}{$\Delta T_{1 / 2} /{ }^{\circ} \mathrm{C}$} & \multirow[t]{2}{*}{$D \times 10^{7}$} \\
\hline & & $T_{i}$ & $T_{m}$ & & & & \\
\hline OS-Raw & 80.66 & 386.10 & 711.56 & 1.18 & 0.58 & 301.12 & 6.67 \\
\hline OS-150 & 81.04 & 405.45 & 455.18 & 1.46 & 0.62 & 192.21 & 20.68 \\
\hline OS-200 & 82.18 & 405.48 & 455.14 & 1.48 & 0.58 & 207.25 & 18.44 \\
\hline OS-250 & 82.93 & 396.05 & 455.77 & 1.48 & 0.56 & 200.31 & 19.01 \\
\hline RH-Raw & 33.15 & 253.66 & 345.08 & 12.26 & 4.61 & 100.42 & 2131.49 \\
\hline RH-150 & 32.85 & 254.32 & 355.62 & 15.38 & 5.51 & 101.54 & 3031.37 \\
\hline RH-200 & 39.02 & 202.79 & 354.82 & 16.28 & 3.60 & 100.7 & 3176.04 \\
\hline RH-250 & 53.43 & 204.13 & 366.22 & 6.48 & 2.07 & 140.55 & 682.10 \\
\hline Mix-Raw & 57.05 & 264.55 & 345.61 & 6.38 & 1.17 & 211.11 & 220.63 \\
\hline Mix-150 & 56.66 & 264.65 & 365.71 & 7.74 & 1.21 & 201.53 & 272.05 \\
\hline Mix-200 & 57.55 & 295.26 & 365.78 & 11.26 & 1.20 & 160.92 & 447.44 \\
\hline Mix-250 & 66.35 & 305.53 & 366.04 & 5.98 & 0.98 & 207.59 & 167.49 \\
\hline $\operatorname{Mix}-\operatorname{Raw}(\mathrm{th})$ & 56.91 & 263.83 & 345.08 & 6.24 & 2.23 & 261.42 & 332.73 \\
\hline Mix-150(th) & 56.95 & 243.99 & 355.38 & 7.74 & 1.13 & 221.09 & 259.82 \\
\hline Mix-200(th) & 60.60 & 213.53 & 355.35 & 8.20 & 0.99 & 200.14 & 323.95 \\
\hline Mix-250(th) & 68.18 & 214.30 & 366.22 & 3.32 & 0.82 & 250.37 & 94.46 \\
\hline
\end{tabular}

Table 6. Pyrolysis characteristics of hydrochars

The comprehensive pyrolysis index (D) can be used to describe the pyrolysis release characteristics of samples. Maximum weight loss Rate of oil shale and Rice Husk Raw materials (OS:1.18\% $\cdot \mathrm{min}^{-1} ; 12.26 \% \cdot \mathrm{min}^{-1}$ ), With the increase of hydrothermal temperature, the $\mathrm{D}$ index of hydrochars increases first and then decreases. When the hydrothermal temperature was $200{ }^{\circ} \mathrm{C}$, the maximum weight loss rate $\left(11.26 \% \cdot \mathrm{min}^{-1}\right)$ appeared, and the comprehensive pyrolysis index reached the maximum value of $447.44 \times 10^{7}$.Except for Mix-Raw, the comprehensive pyrolysis indices of the hydrocharsaceous mixtures are all higher than their theoretical values. This indicates that the co-hydrocharsization of oil shale and rice husk has a synergistic effect,which effectively improves the overall pyrolysis releases characteristics of the mixture.The optimal hydrothermal temperature is around $200^{\circ} \mathrm{C}$.

3.4.3 Pyrolysis Kinetics Analysis

Hydrochars pyrolysis is a chemical reaction to a relatively slow reaction rate, and a large number of references[38] shows that the Coats-Redfern equation is also suitable for calculating pyrolysis kinetic parameters. Therefore, formulations(3) and (4) in section 2.2.3 are used to describe the pyrolysis process of hydrochars, and 
Formulations(6) are used to calculate the pyrolysis kinetic parameters of hydrochars. As shown in Figure 5,the DTG curve of hydrochars of oil shale is the pyrolysis of salts and alkaline earth metal oxides at $600-750^{\circ} \mathrm{C}$, so it is not analyzed here. The calculation results are shown in Table 7.

As shown in Table 7, the activation energy of hydrochars of oil shale reaches the maximum at $150^{\circ} \mathrm{C}$, and the variation range of activation energy is small as the temperature continues to rise, which again indicates that hydrothermal temperature has little influence on hydrochars of oil shale. The activation energy of rice husk hydrochars decreases first and then increases from the increase in hydrothermal temperature, because cellulose hydrothermal reduces volatile content. However, when the temperature reaches $250^{\circ} \mathrm{C}$, a large number of small molecules react to form lignin-like substances, which increases the activation energy required for pyrolysis. Comparing the experimental activation energies with the theoretical values, except Mix-200, the hydrothermal activation energies of the other mixtures were all higher than the theoretical values, mainly due to the synergistic effect of oil shale and rice husk when they were co-hydrothermal, and more macromolecular compounds were generated.

Table 7. Kinetic parameters of hydrochars pyrolysis

\begin{tabular}{|c|c|c|c|c|c|}
\hline Sample & Temperature $T /{ }^{\circ} \mathrm{C}$ & Fitted equation & $\begin{array}{l}\text { Activationenergy } \\
E /\left(\mathrm{kJ} \cdot \mathrm{mol}^{-1}\right)\end{array}$ & $\begin{array}{c}\text { Frequency } \\
\text { factor } A / \mathrm{min}^{-1}\end{array}$ & $\begin{array}{c}\text { Correlationcoefficient } \\
\qquad R^{2}\end{array}$ \\
\hline OS-Raw & $386.10 \sim 564.36$ & $y=-3237.41 x-9.945$ & 26.92 & 3.08 & 0.99 \\
\hline OS-150 & $405.45 \sim 554.19$ & $y=-4581.35 x-8.1347$ & 38.09 & $2.69 \times 10$ & 0.96 \\
\hline OS-200 & $405.48 \sim 554.06$ & $y=-4499.48 x-8.2052$ & 37.41 & $2.46 \times 10$ & 0.94 \\
\hline OS-250 & $396.05 \sim 564.56$ & $y=-4506.9 x-8.28196$ & 37.47 & $2.28 \times 10$ & 0.92 \\
\hline RH-Raw & $253.66 \sim 395.49$ & $y=-7322.44 x-1.3307$ & 60.88 & $3.87 \times 10^{4}$ & 0.99 \\
\hline RH-150 & $254.32 \sim 395.46$ & $y=-6847.06 x-2.1923$ & 56.93 & $1.53 \times 10^{4}$ & 0.99 \\
\hline RH-200 & $202.79 \sim 354.49$ & $y=-2026.62 x-10.706$ & 16.85 & 0.91 & 0.91 \\
\hline RH-250 & $204.13 \sim 396.34$ & $y=-3358.74 x-8.2611$ & 27.92 & $1.74 \times 10$ & 0.96 \\
\hline Mix-Raw & $264.55 \sim 405.86$ & $y=-6514.34 x-3.0319$ & 54.16 & $6.28 \times 10^{3}$ & 0.96 \\
\hline Mix-150 & $264.65 \sim 405.88$ & $y=-7622.54 x-1.4648$ & 63.37 & $3.52 \times 10^{4}$ & 0.98 \\
\hline Mix-200 & $295.26 \sim 406.01$ & $y=-9251.59 x+0.800$ & 76.92 & $4.12 \times 10^{5}$ & 0.97 \\
\hline Mix-250 & $305.53 \sim 406.13$ & $y=-8040.07 x-1.4053$ & 66.85 & $3.94 \times 10^{4}$ & 0.98 \\
\hline Mix-Raw(th) & $263.83 \sim 395.49$ & $y=-5449.09 x-4.8153$ & 45.30 & $8.83 \times 10^{2}$ & 0.98 \\
\hline Mix-150(th) & 243.99 396.34 & $y=-4788.87 x-6.0853$ & 39.81 & $2.18 \times 10^{2}$ & 0.99 \\
\hline Mix-200(th) & $213.53 \sim 315.46$ & $y=-1007.35 x-12.939$ & 83.75 & 1.05 & 0.91 \\
\hline Mix-250(th) & $214.30 \sim 405.48$ & $y=-2226.77 x-10.626$ & 18.51 & 1.08 & 0.93 \\
\hline
\end{tabular}

The correlation coefficients $\mathrm{R}^{2}$ of kinetic parameters are all above 0.91 , indicating that the pyrolysis kinetics results of hydrochars studied by the above kinetic equation are reliable.

\subsubsection{Analysis of Synergistic Effect of Pyrolysis Process}

Many scholars have conducted a lot of research on the synergistic mechanism of biomass and other fuels in the process of co-pyrolysis, but due to the large differences in the composition of different types of biomass and other fuels, the current conclusions are not clear[39-41]. In this study, it was found that the oil shale and rice husk mixed hydrothermal char exhibited a slight synergistic effect in the pyrolysis process when the hydrothermal temperature was lower than $150^{\circ} \mathrm{C}$. When the hydrothermal temperature is higher than $200^{\circ} \mathrm{C}$, the synergistic effect is strong, although the synergistic effect is obviously lower than the combustion process. In the pyrolysis process of the mixture, the devolatilization of rice husk occurred earlier than that of oil shale in stages. Compared with rice husk, shale is a poor hydrogen material, released by rice husk pyrolysis of O-H groups(mainly from dehydroxylation reaction) and $\mathrm{H}$ as a hydrogen donor transferred to the structure of oil shale,suppress the secondary reaction, condensation and crosslinking reaction,etc.)[42] reduce secondary coke and tar in the shale formation. These obvious synergy may promote the pyrolysis behavior of the mixture. At the same time, the raw materials of rice 
husk and oil shale contain certain alkali metals and minerals, and these inorganic substances also have a certain catalytic effect on the thermal transformation of the mixture. Therefore, the synergistic effect of the pyrolysis process can be attributed to the hydrogen supply and the potential catalytic effect of alkali metals in rice husk on the pyrolysis of oil shale. It can be observed from Figure 9 that the synergistic effect at $250^{\circ} \mathrm{C}$ is not significantly better than that at $200^{\circ} \mathrm{C}$, because at a higher hydrothermal temperature, the total volatile content of hydrochars decreases and the polymerization of hydrolyzed intermediates is enhanced, thus weakening the hydrogen supply effect in the pyrolysis process.Therefore, from the perspective of pyrolysis efficiency and economy,the hydrothermal temperature of $200^{\circ} \mathrm{C}$ is considered more appropriate.

\section{Conclusion}

In this paper,the effects of hydrothermal temperature on combustion and pyrolysis characteristics of cohydrocharsation products of oil shale and rice husk were studied,and significant synergistic effects were found during these heat utilization processes. The following conclusions were drawn according to the research content:

1) Different hydrothermal temperatures have little influence on the contents of fixed carbon and volatile matter in oil shale,and the characteristic vibration peaks of O-H,C-O and C-H groups have little change,but they have great influence on the contents of rice husk hydrochars, especially when the hydrothermal temperature is $250^{\circ} \mathrm{C}$. The volatile content of the mixture hydrochars is higher than its theoretical value. With the increase in hydrothermal temperature,the volatile content increases and the vibration of functional group characteristic peaks to weaken.

2) The combustion reaction parameters of the mixture are all higher than the corresponding theoretical values, indicating that there is an obvious synergistic effect of oil shale and rice husk during the cohydrocharsization process, which promotes the mixture to burn more thoroughly and release more heat. About $200{ }^{\circ} \mathrm{C}$ is the optimal hydrothermal temperature for the carbonization pretreatment of cohydrothermal to produce solid fuel to combustion.

3) Due to the hydrogen supply of oil shale and rice husk and the catalysis of minerals and alkali metals,a certain synergistic effect also occurs to the pyrolysis process to promote the pyrolysis reaction. Similarly,these interactions are the most obvious when the hydrothermal temperature is around $240^{\circ} \mathrm{C}$.

Since the synergistic effect of pyrolysis process is lower than that of combustion process,cohydrocharsation products are considered to be more suitable for combustion. The co-hydrocharsization pretreatment effectively improved the fuel characteristics of the mixed feedstock and proved to have the potential to provide more suitable fuel to further heat utilization. These findings have important guiding significance of the efficient utilization of organic waste with low fuel quality and the reduction of energy consumption of thermochemical utilization.

Author Contributions:Funding acquisition and investigation,Y.L.; Methodology and Project administration,Z.K.; Writing - original draft,E.W.All authors have read and agreed to the published version of the manuscript.

Funding: This research was funded by the Scientific research funding 2021 from the Education Department of Liaoning Province(china).

Institutional Review Board Statement: Not applicable.

Informed Consent Statement: Not applicable.

Data Availability Statement: Not applicable.

Conflicts of Interest: The authors declare no conflict of interest.

\section{References}

1. Zhiqin Kang; Yangsheng Zhao; Dong Yang; et al, Review of oil shale in-situ conversion technology. Applied 
Energy. 2020, 269, 115-121

2. Fengtian Bai; Youhong Sun; Yumin Liu; et al, Thermogravimetric Analysis of Huadian Oil Shale Combustion at Different Oxygen Concentrations. Energy \& Fuels. 2016,5, 4450-4456

3. József Popp; Sándor Kovács; Judit Oláh, Bioeconomy: Biomass and biomass-based energy supply and demand. New Biotechnology.2021, 60, 76-84

4. Joseph D.Smith; Vikram Sreedharan; Mark Landon; Zachary P. Smith, Advanced Design Optimization of Combustion Equipment for Biomass Combustion. Renewable Energy. 2020,145, 1597-1607

5. González-Arias; Judith; Sánchez; Marta E.,Hydrocharsization of biomass and waste: A review. Environmental Chemistry Letters. 2021,14,120-135

6. Huihui Liu; Yingquan Chen; Haiping Yang, Hydrocharsization of natural microalgae containing a high ash content. Fuel.2019,249, 441-448

7. Yanpei Song;Hao Zhan;Xiuzheng Zhuang;Xiuli Yin, Synergistic Characteristics and Capabilities of Cohydrocharsization of Sewage Sludge/Lignite Mixtures. Energy \& Fuels. 2019, 33(9), 8735-8745

8. Liping Wang;Yuzhi Chang;Aimin Li;Hydrocharsization for energy-efficient processing of sewage sludge: A review. Renewable and Sustainable Energy Reviews.2019,108, 423-440

9. Xiaoluan Lu;Xiaoqian Ma;Xinfei Chen,Zhongliang Yao;Co-hydrocharsization of polyvinyl chloride and corncob for clean solid fuel production. Bioresource Technology.2020,301, 122763

10. Neng Huang; Peitao Zhao; Sudip Ghosh; Alexander Fedyukhin,Co-hydrocharsization of polyvinyl chloride and moist biomass to remove chlorine and inorganics for clean fuel production. Applied Energy .2019,240,882892

11. Xiaojun Ning;Haipeng Teng; Guangwei Wang; Jianliang Zhang, Physiochemical, structural and combustion properties of hydrochar obtained by hydrocharsization of waste polyvinyl chloride. Fuel.2020,270, 117526

12. Akbar Saba; Pretom Saha;M. Toufiq Reza, Co-Hydrocharsization of coal-biomass blend: Influence of temperature on solid fuel properties. Fuel Processing Technology. 2017,167, 711-720

13. Lichun Chen; Chang Wen; Wenyu Wang; Tianyu Liu, Combustion behaviour of biochars thermally pretreated via torrefaction, slow pyrolysis, or hydrocharsisation and co-fired with pulverised coal. Renewable Energy.2020,161, 867-877

14. Fang Liang; Tao Zhang; Hongzhong Xiang; Xiaomeng Yang, Pyrolysis characteristics of cellulose derived from moso bamboo and poplar. Journal of Thermal Analysis and Calorimetry.2018,132, 1359-1365

15. Laís Ribas; José Manoel dos Reis Neto; Almério Barros França ,The behavior of Irati oil shale before and after the pyrolysis process. Journal of Petroleum Science and Engineering,2017,152, 156-164

16. Marzena Szpiłyk; Renata Lubczak; Małgorzata Walczak, Polyol and polyurethane foam from cellulose hydrolysate. Journal of Chemical Technology and Biotechnology.2020,96, 4,881-889

17. Jun Zou; Haiping Yang; Zhiwei Zeng; Chunfei Wu, Hydrogen production from pyrolysis catalytic reforming of cellulose in the presence of $\mathrm{K}$ alkali metal. International Journal of Hydrogen Energy. 2016,41(25), 1059810607

18. Bo Peng; Huiyan Zhang; Yaping Zhang, Investigation of the relationship between functional groups evolution and combustion kinetics of microcrystalline cellulose using in situ DRIFTS. Fuel.2019, 248,56-64

19. Wei Wang;Yue Ma;Shuyuan Li;Jian Shi, Effect of Temperature on the EPR Properties of Oil Shale Pyrolysates. Energy \& Fuels.2016,2,830-834

20. Hao Rong; Teng Wang; Min Zhou; Hao Wang, Combustion Characteristics and Slagging during CoCombustion of Rice Husk and Sewage Sludge Blends. Energies,2017, 10(4), 438

21. Svetlana Yefremova; Abdurassul Zharmenov; Yurij Sukharnikov; Lara Bunchuk, Rice Husk Hydrolytic Lignin Transformation in Carbonization Process. Molecules.2019, 24(17), 3075

22. Hui Zhang; Xinping Wang; Yanxi Chen; Qiuyan Chen, Insights into the effect of hydrolysis medium on the holocellulose decomposition, furfural, and pseudo-lignin formation, Biofuels. Bioproducts and 
Biorefining.2021,15,4, 1046-1053

23. Haruo Kawamoto, Lignin pyrolysis reactions, Journal of Wood Science.2017.63,117-132

24. Zhao Yu-Ting; Zhang Jian-Hua; Sun Tong-Shan; Yang Zhao-He, Reduced equations to estimate kinetic parameters from non-isothermal TG-DTG or DSC curves. Thermochimica Acta.1993,223,101-108

25. Peng-Gang Liu; Wan-Fen Pu; Ji-Hui Ni; Xian-Ping Ma, Thermal investigation on crude oil oxidation kinetics through TG/DTG and DTA tests. Petroleum Science and Technology.2016,34(7),685-692

26. Hanjian Li; Huanying Chi; Song Hu; Yankui Wang; Gongxiang Song, Comprehensive study on intrinsic combustion behavior of non-premixed coal-biomass pellet at rapid heating rate. Fuel.2021,287, 119496

27. Jamil J. Al Asfar; Ahmad AlShwawra; Ahmad Sakhrieh, Combustion characteristics of solid waste biomass, oil shale, and coal, Energy Sources, Part A: Recovery. Utilization, and Environmental Effects.2017,40,3, 335342

28. Joseph Crapse; Nishant Pappireddi; Meera Gupta; Stanislav Y Shvartsman, Evaluating the Arrhenius equation for developmental processes. Molecular Systems Biology .2021,17(8),9895

29. E. Urbanovici;C. Popescu;E. Segal; Improved Iterative Version of the Coats-Redfern Method to Evaluate NonIsothermal Kinetic Parameters. Journal of Thermal Analysis and Calorimetry.1999, 58,683-700

30. Chonlong Chio;Mohini Sain;Wensheng Qin, Lignin utilization: A review of lignin depolymerization from various aspects. Renewable and Sustainable Energy Reviews.2019,107, 232-249

31. Lin Y S; Ma X Q; Peng X W; et al. Combustion, pyrolysis and char CO2-gasification characteristics of hydrocharsization solid fuel from municipal solid wastes. Fuel, 2016, 181,905-915.

32. Xie C D; Liu J Y; Xie W M, et al. Quantifying thermal decomposition regimes of textile dyeing sludge, pomelo peel, and their blends[J]. Renewable Energy. 2018, 122,55-64.

33. E C; Wang K; Yang Y H, et al. Utilization of sewage-sludge derived hydrochars toward efficient cocombustion with different rank coals: effects of subcritical water conversion and blending scenarios. Energy \& Fuels, 2014, 28(9), 6140-6150.

34. Diao H J; Zhang J;Wang M Y, et al. Effect of high temperature pyrolysis of sewage sludge on characteristics of residual biochar and speciation changes of heavy metals. Environmental Engineering. 2019, 37(3): 29-34.

35. Kambo H S. Dutta A, A comparative review of biochar and hydrochar in terms of production, physico-chemical properties and applications. Renewable and Sustainable Energy Reviews, 2015, 45: 359-378.

36. Yi S; He X M; Zheng H, et al. Characteristics of co-pyrolysis char of sugarcane bagasse and lignite. Chemical Industry and Engineering Progress, 2016, 35(10), 3149-3154.

37. Jian Li; Xiaowei Bai; Yang Fang;Yingquan Chen; Xianhua Wang, Comprehensive mechanism of initial stage for lignin pyrolysis. Combustion and Flame,2020,21,140-156

38. Shurong Wang; Bin Ru; Haizhou Lin; Gongxin Dai, Kinetic Study on Pyrolysis of Biomass Components: A Critical Review. Current Organic Chemistry.2016,20(23), 2489-2513

39. Yuan S; Dai Z H; Zhou Z J, et al. Rapid co-pyrolysis of rice straw and a bituminous coal in a high-frequency furnace and gasification of the residual char. Bioresource Technology. 2012,109, 188-197

40. Salema A A; Afzal M T; Motasemi F, Is there synergy between carbonaceous material and biomass during conventional pyrolysis A TG-FTIR approach. Journal of Analytical and Applied Pyrolysis. 2014, 105:,217-226.

41. Krerkkaiwan S; Fushimi C; Tsutsumi A, et al. Synergetic effect during co-pyrolysis/gasification of biomass and sub-bituminous coal. Fuel Processing Technology. 2013, 115,11-18.

42. Zhang L; Xu S P; Zhao W; et al. Co-pyrolysis of biomass and coal in a free fall reactor. Fuel. 2007, 86(3),353359. 
Figures

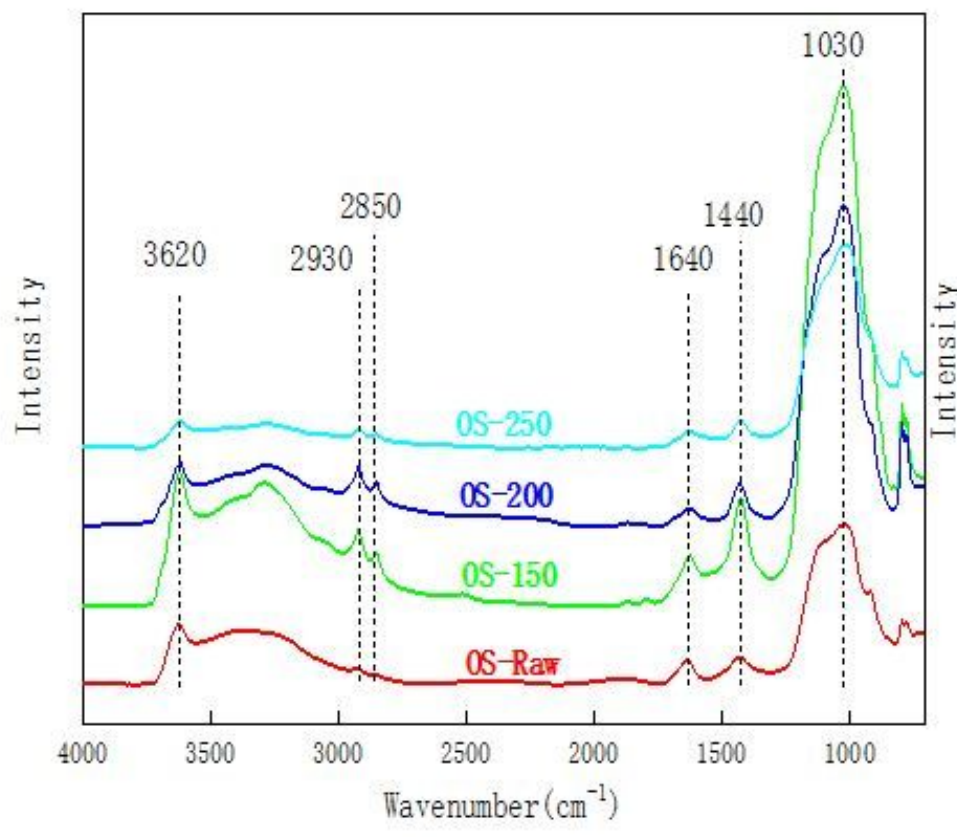

(a)

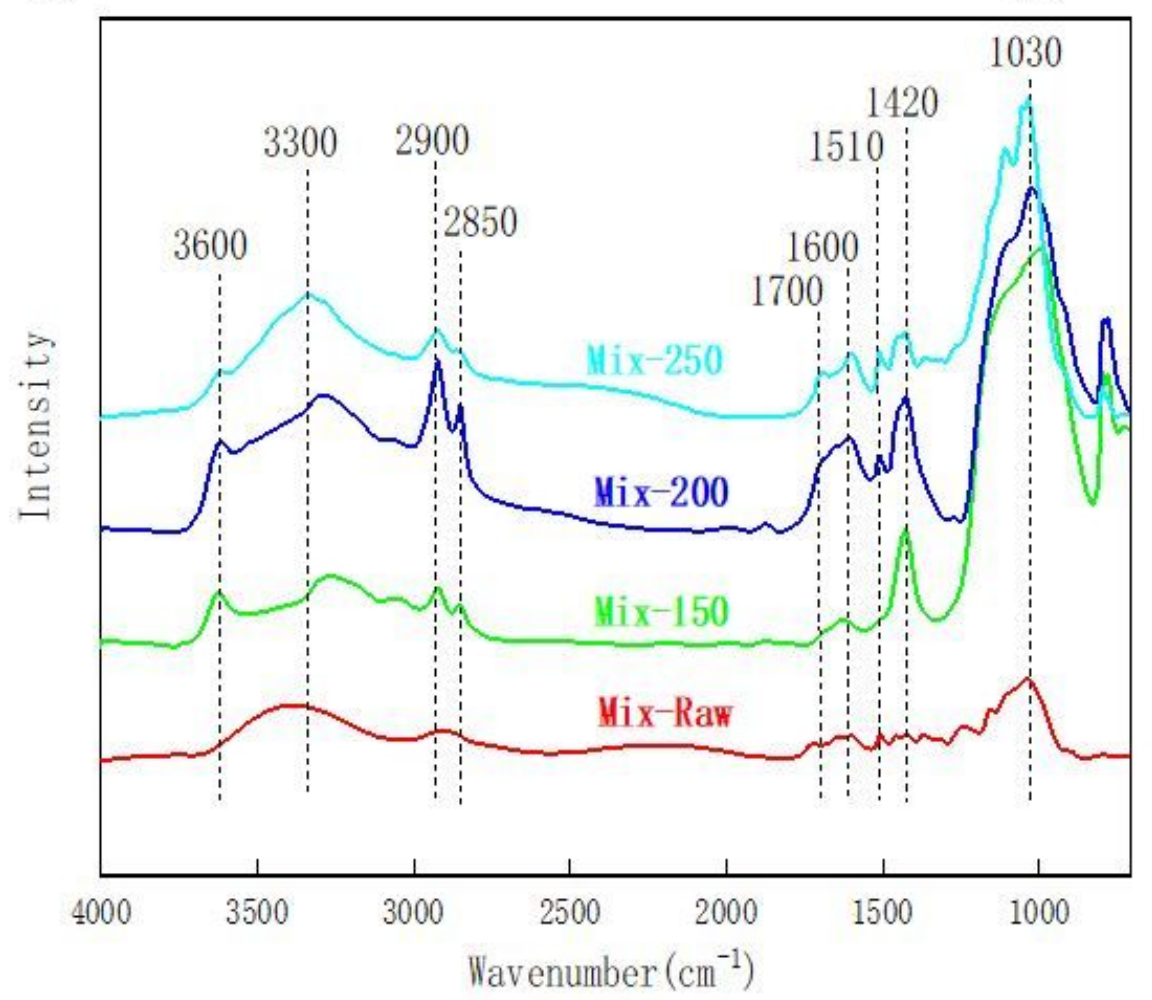

(c)

Figure 1

FTIR spectrum of hydrochars 

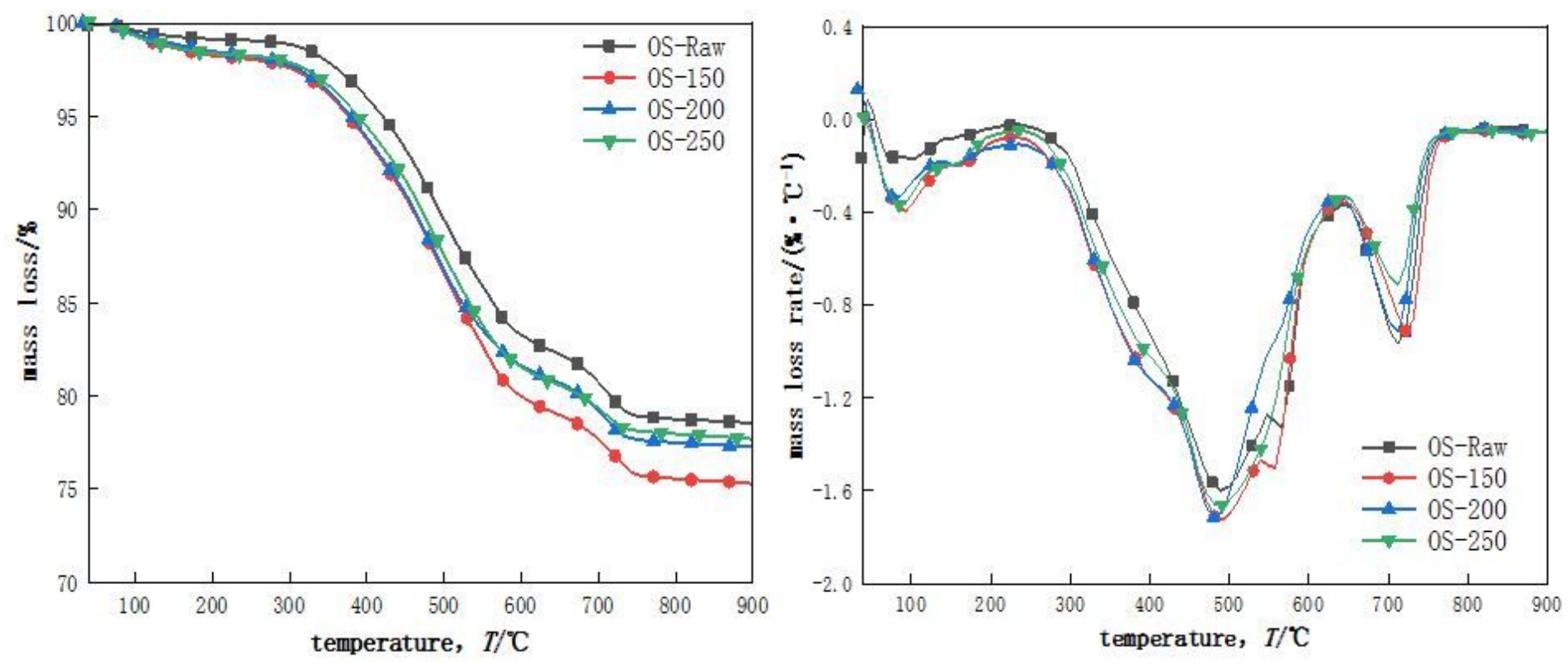

Figure 2

TG and DTG curves of hydrochars combustion in oil shale
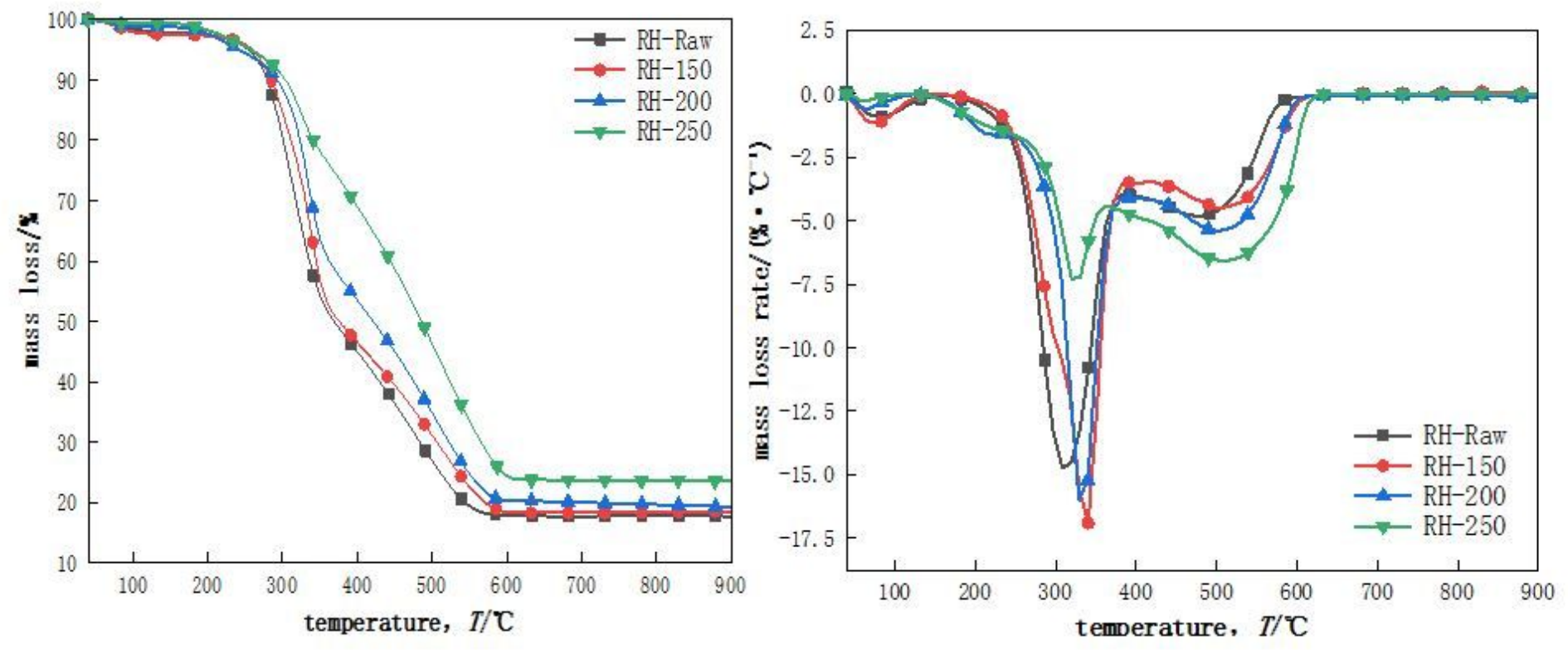

Figure 3

TG and DTG curves of rice husk hydrothermal char combustion 

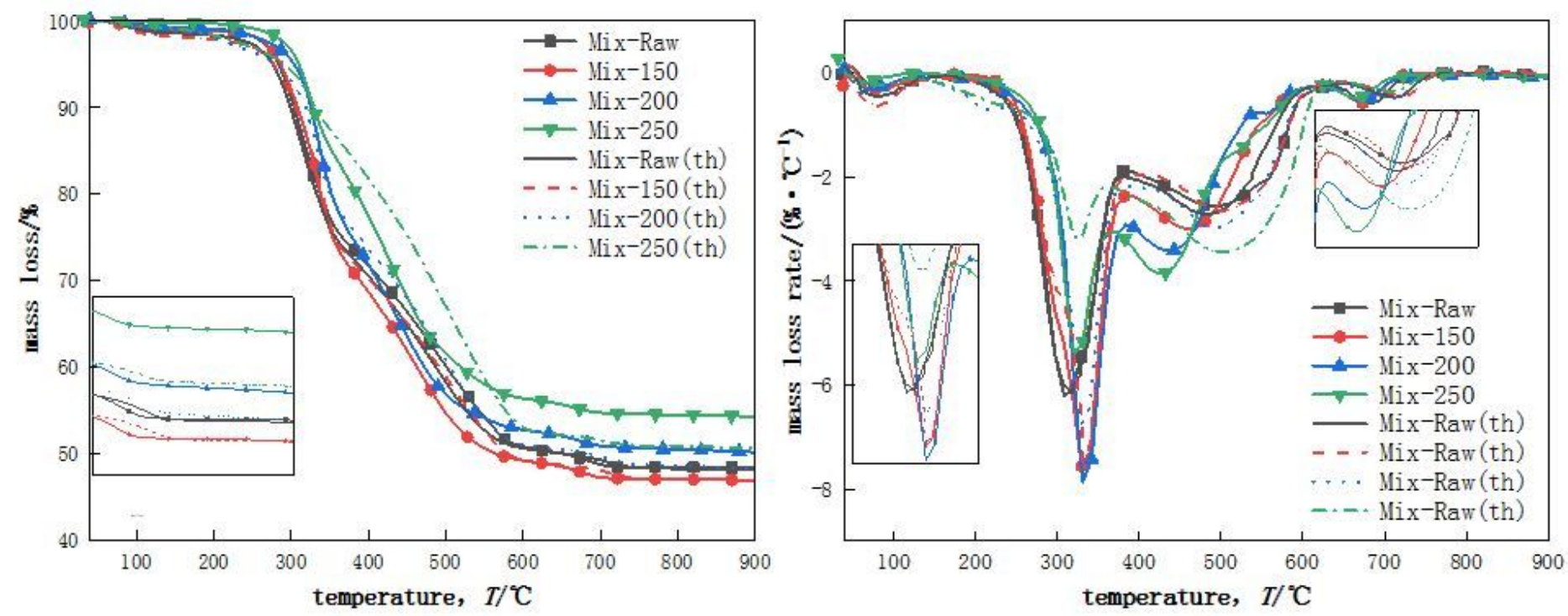

Figure 4

TG and DTG curves of actual and theoretical combustion of mixed hydrochars

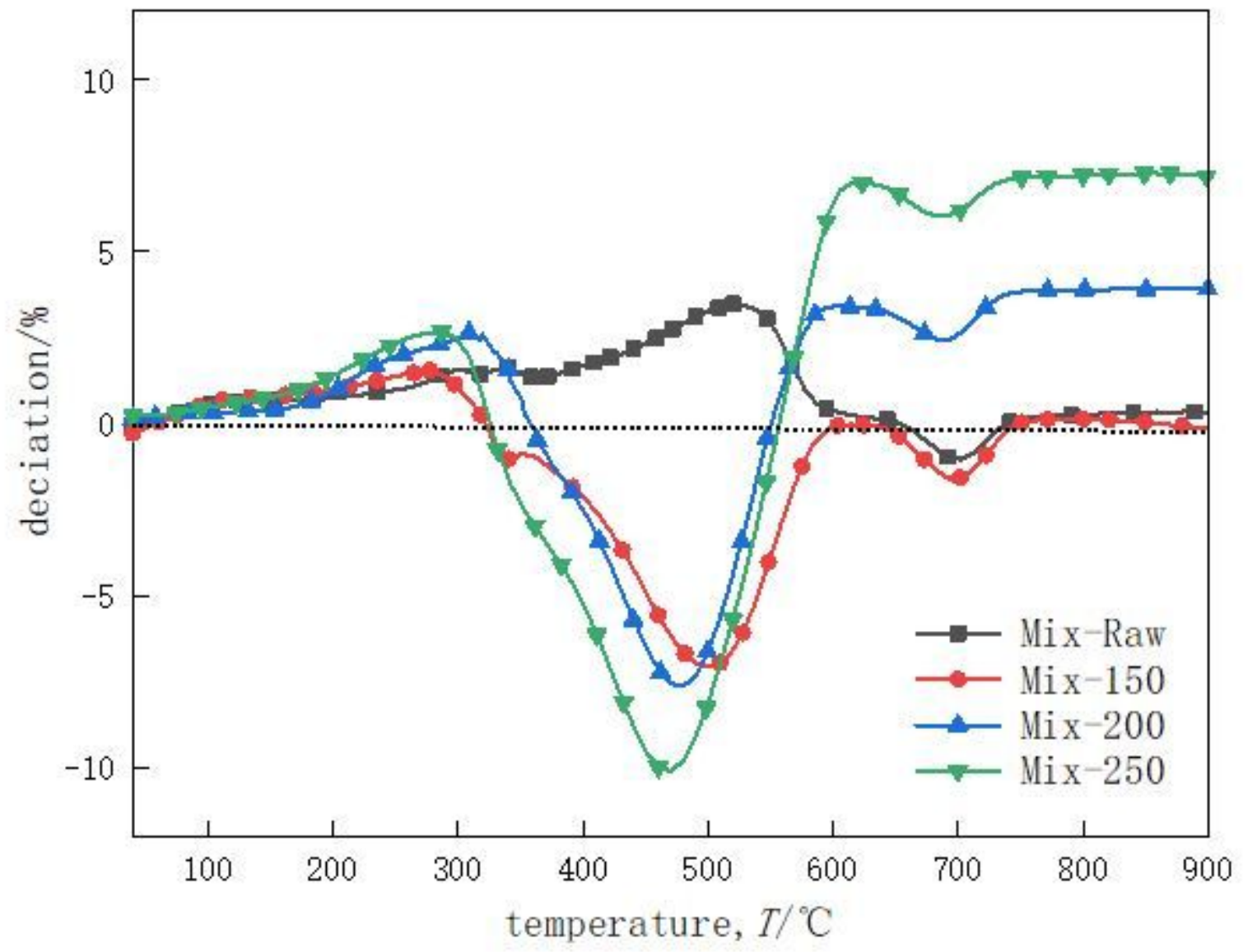

Figure 5

Deviation analysis of experimental and theoretical TG curves during hydrochars combustion process 

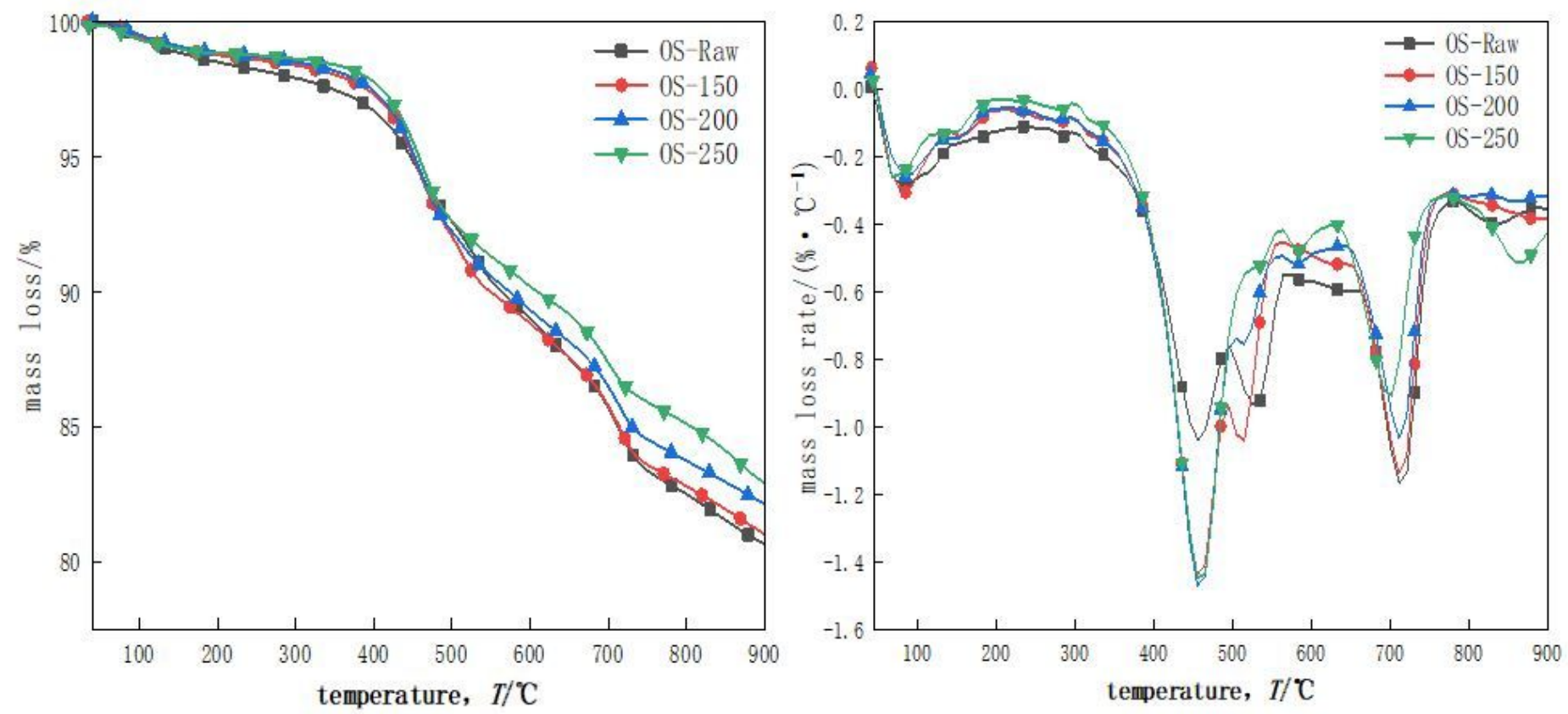

Figure 6

TG and DTG curves of hydrochars pyrolysis of oil shale
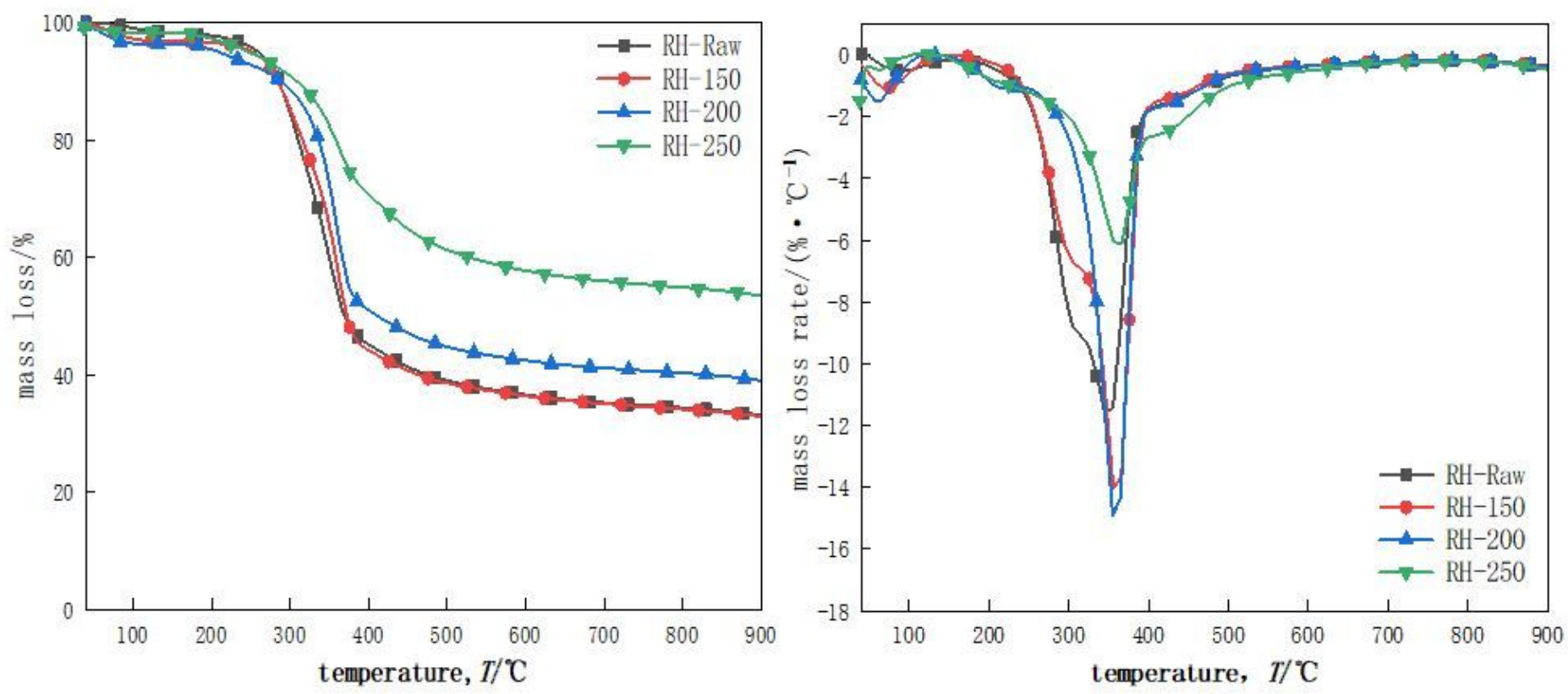

Figure 7

TG and DTG curves of rice husk hydrothermal char pyrolysis 

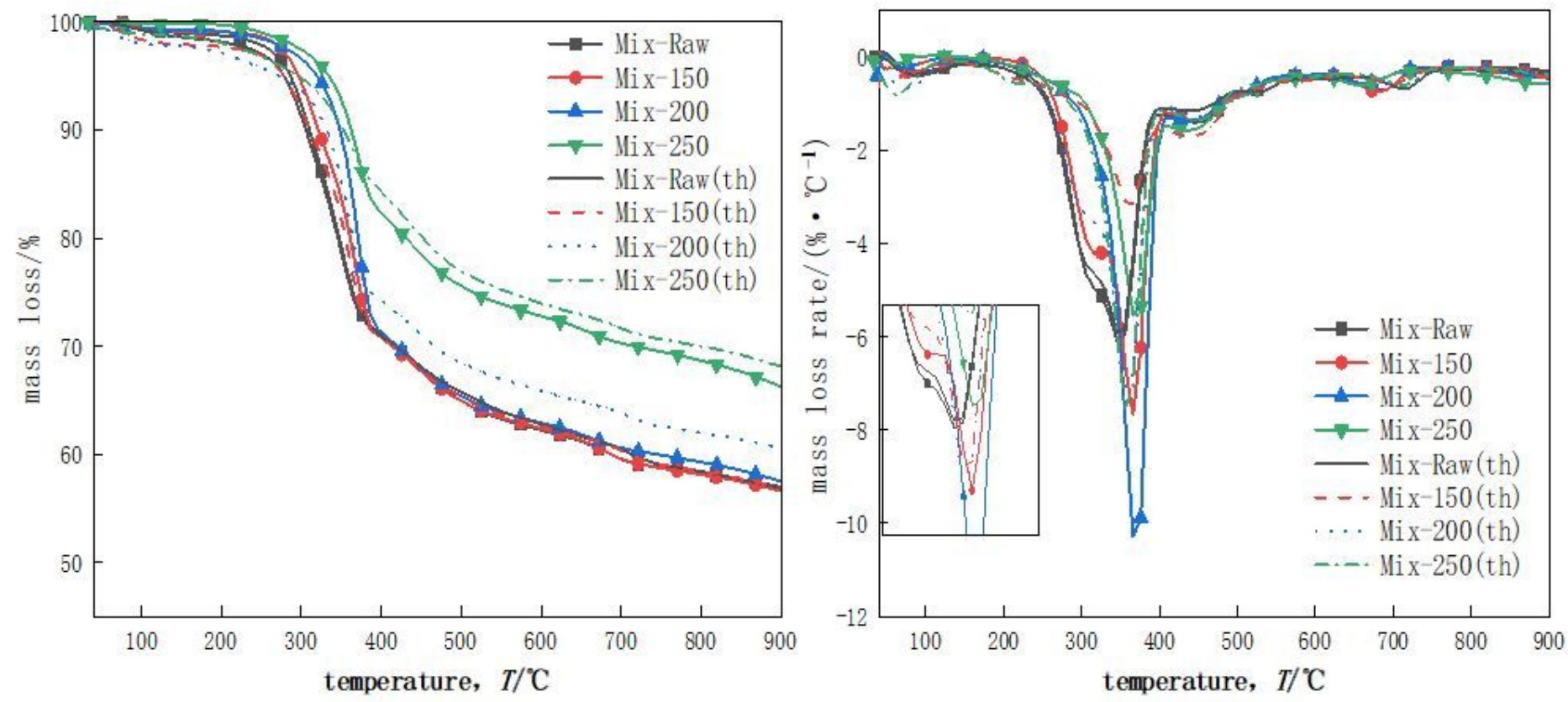

Figure 8

TG and DTG curves of oil shale and rice husk hydrothermal char pyrolysis

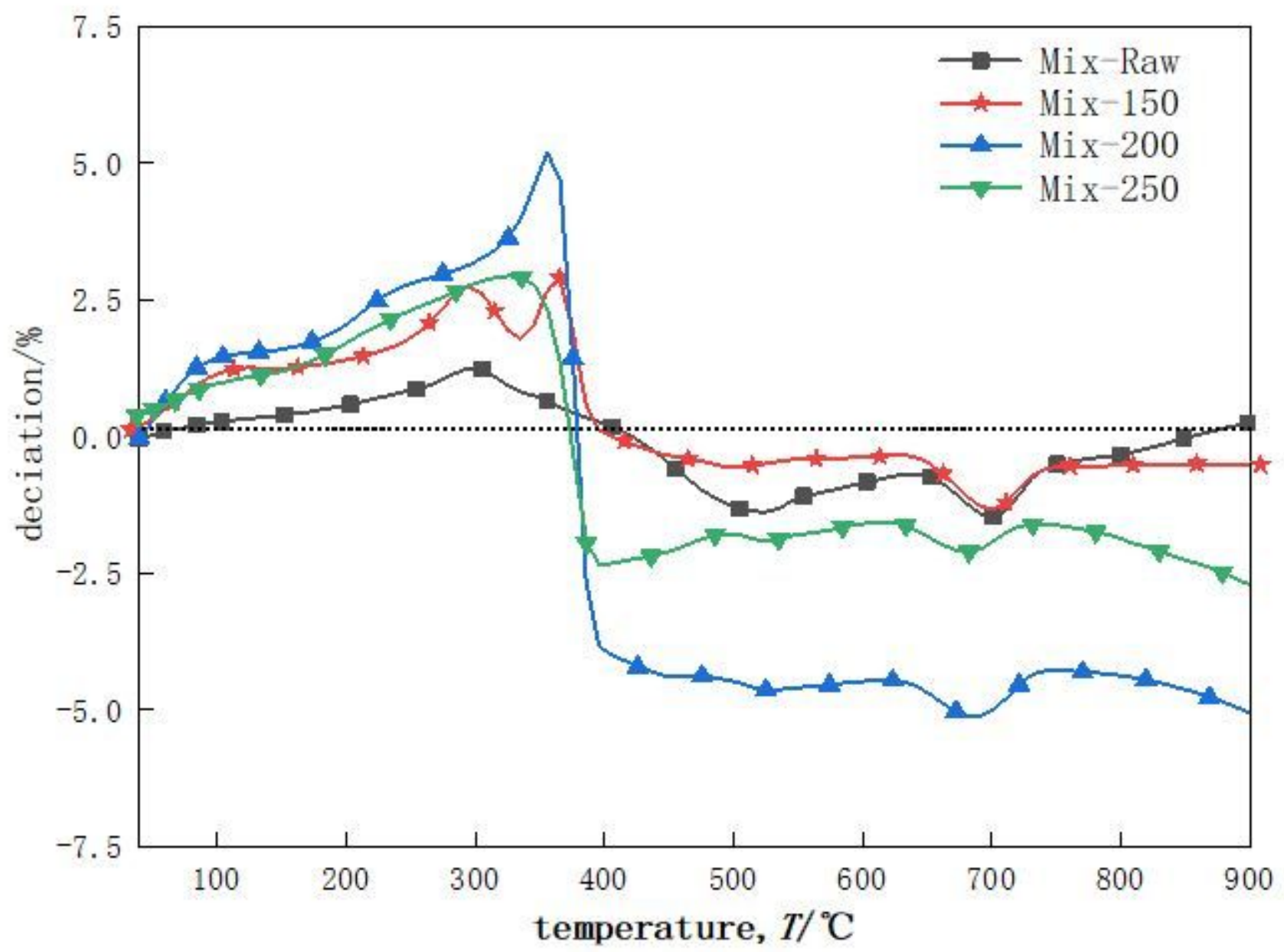

Figure 9 
Deviation analysis of experimental and theoretical TG curves during pyrolysis of hydrochars mixture 